\title{
Daily image-guidance in prostate cancer radiotherapy - implications for treatment margins
}

\author{
G. GLOWACKI*, W. MAJEWSKI, P. WOJCIESZEK, A. TUKIENDORF, D. BODUSZ, G. WOZNIAK, L. MISZCZYK \\ Radiotherapy Department - Maria Sklodowska-Curie Memorial Cancer Center and Institute of Oncology, Branch Gliwice, Poland
}

${ }^{*}$ Corresponding author: geno@poczta.onet.pl

Received May 9, 2014 / Accepted September 4, 2014

\begin{abstract}
Our purpose was to evaluate interfractional organ and patient movement during radiotherapy of prostate cancer and to calculate the necessary CTV to PTV margins. Fifty patients irradiated between 2009 and 2011 were included into the prospective study. The 2D-2D KV system combined with the intraprostatic fiducial marker were used for daily position verification. Based on the 8629 measurements of isocentre displacement an interfractional motion of pelvis and prostate was evaluated. The CTV to PTV margins were calculated. Margins of $0.7 \mathrm{~cm}(\mathrm{AP}), 1 \mathrm{~cm}(\mathrm{SI})$ and $0.35 \mathrm{~cm}(\mathrm{LR})$ are necessary when only bony based IGRT is performed. Margins of $1.0 \mathrm{~cm}, 1.8 \mathrm{~cm}$ and $0.5 \mathrm{~cm}$ in AP, SI and LR directions respectively are necessary in case of no IGRT.There was no clinically relevant changes in patient/target mobility throughout the whole treatment. The IGRT is essential for state of art radiotherapy of prostate cancer. Necessary CTV to PTV margins are much bigger in case of no IGRT performed. Changing of margins size throughout regular treatment is not necessary.
\end{abstract}

Key words: IGRT, prostate cancer, fiducial marker

External beam radiotherapy is one of the main treatment modalities for patients with prostate cancer. Due to the positioning errors it is not possible to irradiate only the tumor volume. This obliges to use the additional margins around the target $[1,2,3,4,5,6,7,8,9,10]$. The CTV to PTV margins are not universal mainly due to variety of positioning verification systems and type of patient immobilization. There are still not many data on the set-up error changes, if daily image-guidance is performed. Image-guided radiotherapy (IGRT) is essential for state-of-art radiotherapy. IGRT becomes widespread, however the most advanced systems are unavailable in some radiation oncology centers particularly in developing countries $[11,12,13,14,15,16,17]$.

IGRT based on 2D-2D KV system is simple and reliable in the routine clinical practice, especially when combined with radio-opaque markers implanted into the prostate gland $[18,19,20]$. It may provide simple and time-sparing patient position verification method, particularly for the centers which do not have the most advanced devices, dedicated for tumor movement tracking/correction.

Abbreviations: IGRT - Image-guided Radiotherapy; CTV - Clinical Target Volume; PTV - Planning Target Volume
If daily IGRT is not available, both prostate and patient displacements should be compensated with fair CTV to PTV margins. If everyday patient position verification is based only on bone structures, some margin should be used for internal movement (set-up error is theoretically eliminated). Intra-prostatic marker allows, indirectly, to image the position of the prostate and to correct the both patient and prostate displacements $[21,22,23,24,25,26]$.

Interfraction motion is not a simple arithmetic sum of an internal error and a set-up error. In fact it is a vector of both random displacements represented by marker shift. Internal error is caused by prostate motion and set-up error is daily patient position fluctuation [27].

The aim of this prospective study is to evaluate an interfraction prostate motion and patient set-up variation during prostate cancer image guided radiotherapy using $2 \mathrm{D}-2 \mathrm{D} \mathrm{KV}$ system in combination with radio-opaque fiducial markers. Based on that we would like to estimate the margins adequate for patients without any IGRT (internal + set-up margin) or those in whom KV IGRT is performed to pelvic bones only. We also would like to verify if there is a need to change the margins during treatment due to positioning errors throughout 38 subsequent fractions of radiotherapy. 


\section{Patients and methods}

Fifty males (51-75 years old) with prostate cancer were included into the study and irradiated in our department of Radiotherapy between 2009 and 2011.

Treatment planning. The Golden Anchor ${ }^{\mathrm{TM}}$ markers were used for image-guidance procedures. The implantation was performed using a needle with diameter of $0.71 \mathrm{~mm}$ and transrectal ultrasonography guidance without anesthesia. Single marker was implanted. Computer tomography was done two weeks later. The planning was performed using 3D conformal or dynamic (intense-modulated or dynamic arc radiotherapy) techniques. Patients were irradiated with $2 \mathrm{~Gy}$ fraction dose to $76 \mathrm{~Gy}$ total dose for prostate (CTV) with added $0.6-1 \mathrm{~cm}$ margin (PTV). Pelvic radiotherapy was planned to $44 \mathrm{~Gy}$, if necessary. All patients were immobilized with pelvic thermoplastics masks with head-and-neck and knee support. The isocentre points were marked on the mask using lasers during simulation to positioning patient properly before the treatment. Every patient had to empty his bladder two hour prior to radiotherapy session and drink $500 \mathrm{ml}$ of still water.

Position verification. The $2 \mathrm{D}-2 \mathrm{D} \mathrm{KV}$ system was used for verification of the patient's isocentre in the two orthogonal planes (0 and 270 degrees). KVs were compared to digitally reconstructed radiographs (DRR). KVs were taken before each fraction of radiotherapy. After DRR and KV images fusion an isocentre displacements in three directions were measured: anterior-posterior (AP), superior-inferior (SI) and left-right (LR). First measurement was completed for bone structures and then to the marker. The manual correction of table position was made in relation to the marker position.

Bone displacements were taken as a set-up error, while prostate markers displacements were taken as a combination (vector) of a set-up error and an internal prostate movement. Estimation from the differences between these two values was calculated separately for each direction and each fraction. It was the prostate displacement.

Statistics. We assumed 11400 measurements (50 patients, 38 fractions, 3 directions measured twice: bony structures and marker displacements). Due to technical problems (KV IGRT system breakdowns in random sessions) we achieved total of $8629(75.7 \%)$ measurements.

The systematic $(\Sigma)$ and the random $(\sigma)$ errors were calculated separately for AP, SI, LR directions with formulas presented below:

$$
\sum=\sqrt{\frac{1}{N-1} \sum_{j=1}^{N}\left(m_{j}-\bar{M}\right)^{2}} \quad \sigma=\sqrt{\frac{1}{N} \sum_{j=1}^{N}\left(s d_{j}\right)^{2}}
$$

where: $s d_{j}$ is standard deviation of patient $j ; M^{-}$is population mean systematic deviation; $m_{j}$ is patient $j$ mean systematic deviation; $\mathrm{N}$ is total number of patients.

The evaluation of the margins to receive PTV (assumed margins needed for $95 \%$ coverage) was based on the formula proposed by van Herk. It included interfractional motion of the patient (set-up margin), the prostate gland (internal margin) or the combination of both (vector margin).

\section{Margin $=2.5 \Sigma+0.7 \sigma$}

The internal margin without set-up margin may be applied while image guidance based on bone structures only is performed. The vector margin compensates both organ and patient motion. Such margin is necessary when IGRT is not used.

To evaluate the rate (increase or decrease of isocentre displacements size) of positioning errors change throughout 38 subsequent fractions of radiotherapy a multilevel (hierarchical) modeling of the data with mixed effects was conducted. This was aimed to answer if patient/tumor movements tend to change and what is its trend during few weeks of external beam radiotherapy

The computation was done with R platform.

\section{Results}

The Gaussian distribution of measured displacements of isocentres showed that mean patient displacement (set-up error) was $0.19 \mathrm{~cm}(\mathrm{SD}=0.27 \mathrm{~cm}), 0.11 \mathrm{~cm}(\mathrm{SD}=0.82 \mathrm{~cm})$ and $-0.05 \mathrm{~cm}(\mathrm{SD}=0.23 \mathrm{~cm})$ for $\mathrm{AP}, \mathrm{SI}$ and $\mathrm{LR}$ directions, respectively. The largest set-up error in SI direction was recorded.

The vector of both pelvis and prostate displacements (combination of set-up and internal errors) represented by marker was $0.16(\mathrm{SD}=0.40 \mathrm{~cm}), 0.09 \mathrm{~cm}(\mathrm{SD}=0.82 \mathrm{~cm})$ and $-0.04 \mathrm{~cm}(\mathrm{SD}=0.22 \mathrm{~cm})$ for AP, SI and LR directions, respectively (Table 1).

Prostate movement was calculated from the differences between the marker and bony structures displacements. The range of the internal error was the biggest in the SI direction ( range $=-1.6-2.2 \mathrm{~cm}$ ) and than in the AP direction ( range $=-2.1-1.1 \mathrm{~cm})$.

For the SI direction CTV to PTV margins estimation based on the van Herk's formula were $1.76 \mathrm{~cm}$ for the set-up error, $0.97 \mathrm{~cm}$ for the internal error and $1.81 \mathrm{~cm}$ for the combination

Table 1. Interfraction patient and prostate motion.

\begin{tabular}{lcccc}
\hline & Direction & Mean $[\mathrm{cm}]$ & SD $[\mathrm{cm}]$ & Range $[\mathrm{cm}]$ \\
\hline \multirow{3}{*}{ Set-up error } & AP* & 0.19 & 0.27 & $-0.6-1.1$ \\
& SI† & 0.11 & $\mathbf{0 . 8 2}$ & $-2.9-3.0$ \\
& LR $\neq$ & -0.05 & 0.23 & $-1.4-1.4$ \\
\hline \multirow{3}{*}{ Internal error } & AP & -0.02 & $\mathbf{0 . 3 2}$ & $-2.1-1.1$ \\
& SI & 0.01 & $\mathbf{0 . 4 0}$ & $-1.6-2.2$ \\
\hline Vector & LR & 0.02 & 0.16 & $-0.9-0.8$ \\
(combination of set-up & AP & 0.16 & 0.40 & $-2.0-1.6$ \\
and internal errors) & SI & 0.09 & $\mathbf{0 . 8 2}$ & $-2.7-2.9$ \\
& LR & -0.04 & 0.22 & $-1.3-1.3$ \\
\hline
\end{tabular}

* anterior - posterior; † superior - interior; $\ddagger$ left - right 


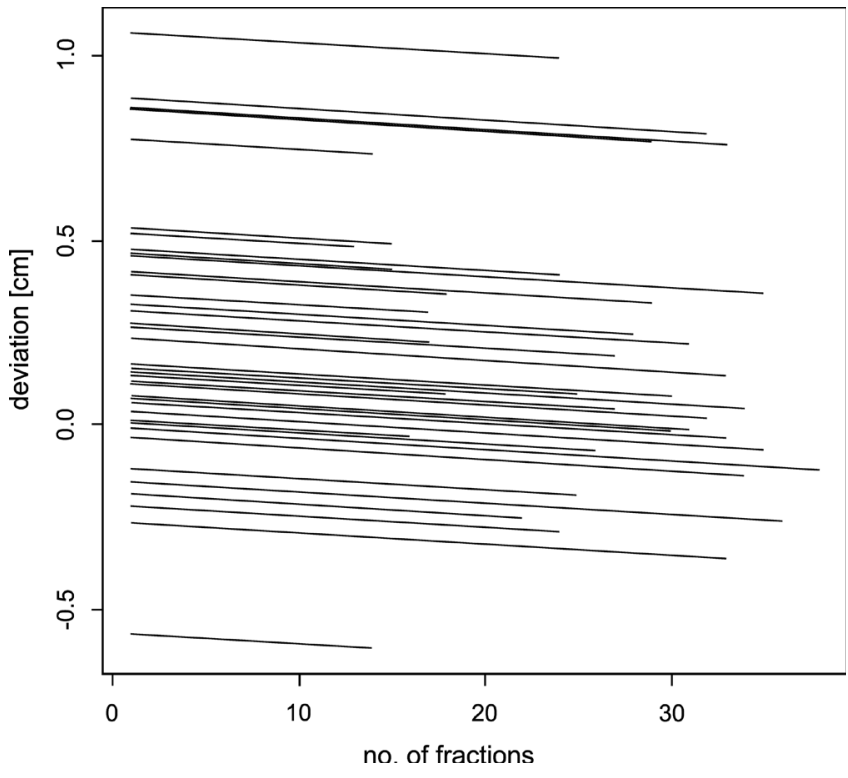

Figure 1. Deviations of isocentre positioning error in AP direction throughout radiotherapy (each line represents one patient)

of both errors respectively. AP direction margin estimations were $0.66 \mathrm{~cm}$ for the set-up error, $0.73 \mathrm{~cm}$ for the internal error and $1 \mathrm{~cm}$ for the combination of both errors. The smallest margins were estimated for the LR direction. These were 0.48 $\mathrm{cm}, 0.35 \mathrm{~cm}$ and $0.51 \mathrm{~cm}$ for the set-up, internal and combination of both errors (Table 2).

A multilevel (hierarchical) modeling of the data with mixed effects showed statistically significant changes in the patient/ prostate mobility in the AP direction throughout the treatment. These had low magnitude, which means little clinical relevance. The average reduction of isocentre deviations during daily radiotherapy was $0.003 \mathrm{~cm}$ per fraction ( $\mathrm{p}-0.0008)$ It was around $0.1 \mathrm{~cm}$ throughout the whole treatment (Table 3 ).

Table 2. Systematic, random errors and margins to receive optimal PTV due to interfraction motion.

\begin{tabular}{lcccc}
\hline & Direction & $\Sigma$ & $\sigma$ & Margin $[\mathrm{cm}]$ \\
\hline \multirow{2}{*}{ Set-up margin } & AP* & 0.22 & 0.17 & 0.66 \\
(SM) & SI $\dagger$ & 0.52 & 0.66 & 1.76 \\
& LR $\ddagger$ & 0.14 & 0.19 & 0.48 \\
\hline \multirow{2}{*}{ Internal mar- } & AP & 0.23 & 0.23 & 0.73 \\
gin (IM)§ & SI & 0.31 & 0.27 & 0.97 \\
& LR & 0.11 & 0.12 & 0.35 \\
Vector margin & AP & 0.32 & 0.26 & 1.00 \\
(SM+IM) & SI & 0.54 & 0.66 & 1.81 \\
& LR & 0.16 & 0.16 & 0.51 \\
\hline
\end{tabular}

*anterior-posterior; †superior-inferior; $\ddagger$ left-right; $₫$ necessary margins if KV IGRT alignment to bony structures enable; combination of set-up and internal margins, necessary margins if alignment only to centering points on thermoplastic mask enable without IGRT
Isocentre deviations in AP direction are shown on graph. The slope of each line is gradual, almost straight (Fig. 1).

\section{Discussion}

This study shows that daily organ positioning is essential for appropriate radiotherapy of prostate cancer patients. However, image guided radiotherapy is not performed in all centers due to limited availability of such devices especially in developing countries. Radiotherapy based on KV's to bone pelvis is reasonable option for centers not equipped with the most advanced positioning verification systems. Intraprostatic marker implantation may reduce PTV significantly. The adequate CTV to PTV margins of $0.7 \mathrm{~cm}$ in AP, $1.0 \mathrm{~cm}$ in SI and $0.35 \mathrm{~cm}$ in LR seem adequate in case of pelvic bones verification without fiducial. Without any image-guidance, only thermoplastic mask immobilization, sufficient CTV to PTV margins should be $1 \mathrm{~cm}$ for AP direction, $1.8 \mathrm{~cm}$ for SI direction and $0.5 \mathrm{~cm}$ for LR direction. It makes irradiated volume larger and, of course, may increase treatment toxicity.

Our hypothesis that set-up and internal errors decrease throughout 38 fractions of radiotherapy was not confirmed. Although change in AP direction was statistically significant ( $\mathrm{p}-0,0008$ ) it was clinically irrelevant. This means there is no need to change margins throughout regular treatment. In available scarce data decrease in interfractional error was found in patients with special diet. This was linked to less fecal gasses in rectum [28]. Set-up error analyses showed rather its increase, however it could be biased due to non-daily image guidance protocols [13,29,30,31].

Prostate cancer radiotherapy protocol variations or slightly different evaluation methods among radiotherapy centers may influence the results of various studies on positioning errors. Many publications describe portal verification $[23,32,33,34,35,36,37]$. Our group of prostate cancer patients treated with IGRT based on daily kVs and intraprostatic markers is the largest available.

Balter et al. published results of MV portal IGRT with radio-opaque markers in 10 prostate cancer patients. They proposed almost the same AP and LR direction margins as we did, however SI margin was over two-times smaller than ours. They suggested AP and LR directions as a natural prostate

Table 3. Isocentre deviations throughout 38 fractions of prostate cancer radiotherapy (multilevel modelling).

\begin{tabular}{lcccc}
\hline & Direction & Slope $[\mathrm{cm}]$ & SE & p-value \\
\hline Bony structures & AP* & -0.0001 & 0.0006 & 0.8763 \\
& SI $\dagger$ & 0.0020 & 0.0023 & 0.3960 \\
& LR $\ddagger$ & 0.0005 & 0.0007 & 0.4413 \\
Marker & AP & $\mathbf{- 0 . 0 0 3 0}$ & $\mathbf{0 . 0 0 0 9}$ & $\mathbf{0 . 0 0 0 8}$ \\
& SI & 0.0031 & 0.0024 & 0.1991 \\
& LR & 0.0012 & 0.0006 & 0.0602 \\
\hline
\end{tabular}

* anterior - posterior; $\uparrow$ superior - inferior; $\ddagger$ left - right 
movement directions [33]. Other publication shows reduction of margins, if patient position adjustment was based on fiducial markers. When IGRT was not available, their LR margin would have to be two-times larger than ours. Moreover their SI margin was twice smaller for no IGRT situation, if compared to our SI margin. Margins in AP direction were comparable [23]. Enmark et al. reported daily verification based on three intraprostatic markers and ExactTrac Xray $6 D^{\circ}$ system [38]. When patient positioning was based on infrared skin markers only, AP and LR margins were similar to our results with patient alignment to isocenter drawn on plastic mask. If we compare our results to those published by Chen et al., again their SI direction margin was around two-times smaller than ours [39]. On the other hand they had LR direction margin around two-times larger than that proposed by us. In one of most recent publications by Langsenlehner et al. [40] AP and LR directions margins were larger then ours. SI direction margins were slightly smaller. So in our opinion isocenter points drawn on thermoplastic masks (our department practice) may have impact on larger set-up errors in SI direction. The mobility of the patients along SI direction is the largest in this type of immobilization system, however with plastic mask LR and AP displacements seem to be smaller. Moreover patient immobilization may decrease the risk of patient intrafractional motion (wriggling). Therefore, the advantages of such positioning seem to balance its disadvantages. The AP direction prostate movement is also linked with proximity of the rectum and bladder. It can be avoided with appropriate dietary instructions (e.g. non flatulent diet, fluid amount prior to irradiation, administration of an antiflatulence medication).

The practice of IGRT was addressed in national surveys in 2010. Only $36.1 \%$ responses were received from 1600 radiation oncologist surveyed in United States of America. Although 93.5\% of them used IGRT ( $82.3 \%$ when MV portals excluded), most of them used it rarely (less than $25 \%$ of patients) or infrequently ( $25 \%-50 \%$ of patients). KV image-guidance was used by $57.7 \%$ of US radiation oncologists. From 50 radiation oncology centers in United Kingdom only 26 had at least one $\mathrm{kV}$ IGRT machine (23 centers used KVs). It was expected to increase this number to 43 by 2010.115 from 139 japanese major radiation oncology centers took part in national survey on use of new technologies in prostate cancer radiotherapy. 70 (60.9\%) centers used IGRT, 54 of which used KVs for prostate radiotherapy image-guidance. 33 centers matched patient position to bones, 20 to prostate and 9 to implanted markers. Daily IGRT was carried out in 60 centers. IGRT with regular intervals was performed in nine. National Comprehensive Cancer Network guidelines allow daily IGRT only for prostate cancer patients since 2012, however it can be unachievable for many radiotherapy centres, particularly in developing countries $[41,42,43]$.

Although IGRT is supposed to have its place in modern radiotherapy it seems that it is still not used widespread even in developed countries. This means that guidelines on CTVPTV margins in such situations are still useful.
The use of daily IGRT eliminates most of errors associated with interfractional motion, but, naturally, does not allow the complete elimination of margins due to the presence of intrafraction motion, the risk of systematic errors in the process of treatment preparation, imaging, delineation errors etc.

There is no uniform and exact recommendation on prostate PTV, presently. Published margins range from 5 to $12 \mathrm{~mm}$ and more $[15,22,27,40,44,45,46,47,48,49,50,51]$. However, the CTV to PTV margins may be different in various situations based on policy of RT planning of treating centers. The results of this study demonstrate that use of IGRT minimize margins caused by interfraction motion. The most probable clinical impact is the possibility of decreasing the volume of irradiated rectum and bladder and radiotherapy toxicity reduction. We continue to collect and analyze these data.

In conclusion, the IGRT is essential for state of art radiotherapy of prostate cancer. Necessary CTV to PTV margins are much bigger in case if no IGRT is performed.

The additional CTV to PTV margin of $0.7 \mathrm{~cm}(\mathrm{AP}), 1 \mathrm{~cm}$ (SI) and $0.35 \mathrm{~cm}$ (LR) is necessary when there is onle bony based patient position correction possible. When there is no IGRT performed margins of $1.0 \mathrm{~cm}, 1.8 \mathrm{~cm}$ and $0.5 \mathrm{~cm}$ in AP, SI and LR directions respectively are necessary.

The variability of patient positioning errors in throughout 38 fractions of radiotherapy is clinically irrelevant. There is no need to change the size of margins defined while treatment plan is prepared.

\section{References}

[1] BRENNER DJ, MARTINEZ AA, EDMUNDSON GK, MITCHELL C, THAMES HD, et al. (2002) Direct evidence that prostate tumors show high sensitivity to fractionation (low alpha/beta ratio), similar to late-responding normal tissue. Int J Radiat Oncol Biol Phys 52: 6-13. http://dx.doi. org/10.1016/S0360-3016(01)02664-5

[2] KUPELIAN P, KUBAN D, THAMES H, LEVY L, HORWITZ E, et al. (2005) Improved biochemical relapse-free survival with increased external radiation doses in patients with localized prostate cancer: the combined experience of nine institutions in patients treated in 1994 and 1995. Int J Radiat Oncol Biol Phys 61: 415-419. http://dx.doi.org/10.1016/j. ijrobp.2004.05.018

[3] DEARNALEY DP, SYDES MR, GRAHAM JD, AIRD EG, BOTTOMLEY D, et al. (2007) Escalated-dose versus standard-dose conformal radiotherapy in prostate cancer: first results from the MRC RT01 randomised controlled trial. Lancet Oncol 8: 475-487. http://dx.doi.org/10.1016/S14702045(07)70143-2

[4] GRANFORS T, MODIG H, DAMBER JE, TOMIC R (2006) Long-term followup of a randomized study of locally advanced prostate cancer treated with combined orchiectomy and external radiotherapy versus radiotherapy alone. J Urol 176: 544-547. http://dx.doi.org/10.1016/j.juro.2006.03.092

[5] ROACH M, 3RD, DESILVIO M, LAWTON C, UHL V, MACHTAY M, et al. (2003) Phase III trial comparing whole- 
pelvic versus prostate-only radiotherapy and neoadjuvant versus adjuvant combined androgen suppression: Radiation Therapy Oncology Group 9413. J Clin Oncol 21: 1904-1911. http://dx.doi.org/10.1200/JCO.2003.05.004

[6] D'AMICO AV, COTE K, LOFFREDO M, RENSHAW AA, SCHULTZ D (2002) Determinants of prostate cancer-specific survival after radiation therapy for patients with clinically localized prostate cancer. J Clin Oncol 20: 4567-4573. http:// dx.doi.org/10.1200/JCO.2002.03.061

[7] KUPELIAN PA, POTTERS L, KHUNTIA D, CIEZKI JP, REDDY CA, et al. (2004) Radical prostatectomy, external beam radiotherapy $<72 \mathrm{~Gy}$, external beam radiotherapy $>$ or $=72 \mathrm{~Gy}$, permanent seed implantation, or combined seeds/external beam radiotherapy for stage $\mathrm{T} 1-\mathrm{T} 2$ prostate cancer. Int J Radiat Oncol Biol Phys 58: 25-33. http://dx.doi.org/10.1016/ S0360-3016(03)00784-3

[8] POLLACK A, ZAGARS GK, STARKSCHALL G, ANTOLAK JA, LEE JJ, et al. (2002) Prostate cancer radiation dose response: results of the M. D. Anderson phase III randomized trial. Int J Radiat Oncol Biol Phys 53: 1097-1105. http://dx.doi. org/10.1016/S0360-3016(02)02829-8

[9] SYLVESTER JE, GRIMM PD, WONG J, GALBREATH RW, MERRICK G, et al. Fifteen-year biochemical relapse-free survival, cause-specific survival, and overall survival following I(125) prostate brachytherapy in clinically localized prostate cancer: Seattle experience. Int J Radiat Oncol Biol Phys 81: 376-381. http://dx.doi.org/10.1016/j.ijrobp.2010.05.042

[10] GODLEY A, AHUNBAY E, PENG C, LI XA Accumulating daily-varied dose distributions of prostate radiation therapy with soft-tissue-based kV CT guidance. J Appl Clin Med Phys 13: 3859.

[11] BODA-HEGGEMANN J, LOHR F, WENZ F, FLENTJE M, GUCKENBERGER M kV cone-beam CT-based IGRT: a clinical review. Strahlenther Onkol 187: 284-291. http://dx.doi. org/10.1007/s00066-011-2236-4

[12] KORREMAN S, RASCH C, MCNAIR H, VERELLEN D, OELFKE U, et al. The European Society of Therapeutic Radiology and Oncology-European Institute of Radiotherapy (ESTROEIR) report on 3D CT-based in-room image guidance systems: a practical and technical review and guide. Radiother Oncol 94: 129-144. http://dx.doi.org/10.1016/j.radonc.2010.01.004

[13] LIU H, WU Q A "rolling average" multiple adaptive planning method to compensate for target volume changes in imageguided radiotherapy of prostate cancer. J Appl Clin Med Phys 13: 3697.

[14] SLAGMOLEN P, HERMANS J, MAES F, BUDIHARTO T, HAUSTERMANS $\mathrm{K}$, et al. Fast, accurate, and robust automatic marker detection for motion correction based on oblique $\mathrm{kV}$ or MV projection image pairs. Med Phys 37: 1554-1564. http://dx.doi.org/10.1118/1.3355871

[15] LERMA FA, LIU B, WANG Z, YI B, AMIN P, et al. (2009) Role of image-guided patient repositioning and online planning in localized prostate cancer IMRT. Radiother Oncol 93: 18-24. http://dx.doi.org/10.1016/j.radonc.2009.06.011

[16] THONGPHIEW D, WU QJ, LEE WR, CHANKONG V, YOO S, et al. (2009) Comparison of online IGRT techniques for prostate IMRT treatment: adaptive vs reposition- ing correction. Med Phys 36: 1651-1662. http://dx.doi. org/10.1118/1.3095767

[17] MISZCZYK L, LESZCZYNSKI W, SZCZEPANIK K, MAJEWSKI W (2008) [Comparison of two image guided radiation therapy (IGRT) methods used for prostate cancer patients--CBCT and 2D-2D kV]. Przegl Lek 65: 315-320.

[18] BODUSZ D, GLOWACKI G, LESZCZYNSKI W, MISTA W, MISZCZYK L [Evaluation of GoldAnchorTM fiducial marker migration during the planning of radiation treatment for patients with prostate cancer]. Przegl Lek 70: 11-14.

[19] MCGARY JE, GRANT W, 3rd (2000) A clinical evaluation of setup errors for a prostate immobilization system. J Appl Clin Med Phys 1: 138-147. http://dx.doi.org/10.1120/1.1315581

[20] YOON WS, YANG DS, LEE JA, LEE S, PARK YJ, et al. The extent and serial pattern of interfractional variation in patients with whole pelvic irradiation: a study using a kilovoltage orthogonal on-board imager. J Appl Clin Med Phys 13: 3636.

[21] BEAUliEU L, AUBin S, TASCHEREAU R, POUliot J, VIGNEAULT E (2002) Dosimetric impact of the variation of the prostate volume and shape between pretreatment planning and treatment procedure. Int J Radiat Oncol Biol Phys 53: 215-221. http://dx.doi.org/10.1016/S0360-3016(02)02729-3

[22] VAN DEN HEUVEL F, POWELL T, SEPPI E, LITTRUPP P, KHAN M, et al. (2003) Independent verification of ultrasound based image-guided radiation treatment, using electronic portal imaging and implanted gold markers. Med Phys 30: 2878-2887. http://dx.doi.org/10.1118/1.1617354

[23] VAN DEN HEUVEL F, FUGAZZI J, SEPPI E, FORMAN JD (2006) Clinical application of a repositioning scheme, using gold markers and electronic portal imaging. Radiother Oncol 79: 94-100. http://dx.doi.org/10.1016/j.radonc.2006.03.002

[24] KILLORAN JH, KOOY HM, GLADSTONE DJ, WELTE FJ, BEARD CJ (1997) A numerical simulation of organ motion and daily setup uncertainties: implications for radiation therapy. Int J Radiat Oncol Biol Phys 37: 213-221. http:// dx.doi.org/10.1016/S0360-3016(96)00477-4

[25] KEALL PJ, BECKHAM WA, BOOTH JT, ZAVGORODNI SF, OPPELAAR M (1999) A method to predict the effect of organ motion and set-up variations on treatment plans. Australas Phys Eng Sci Med 22: 48-52.

[26] HANDSFIELD LL, YUE NJ, ZHOU J, CHEN T, GOYAL $S$ Determination of optimal fiducial marker across imageguided radiation therapy (IGRT) modalities: visibility and artifact analysis of gold, carbon, and polymer fiducial markers. J Appl Clin Med Phys 13: 3976.

[27] VAN HERK M, BRUCE A, KROES AP, SHOUMAN T, TOUW A, et al. (1995) Quantification of organ motion during conformal radiotherapy of the prostate by three dimensional image registration. Int J Radiat Oncol Biol Phys 33: 1311-1320. http://dx.doi.org/10.1016/0360-3016(95)00116-6

[28] GRAF R, BOEHMER D, NADOBNY J, BUDACH V, WUST $\mathrm{P}$ Appropriate patient instructions can reduce prostate motion. Radiat Oncol 7: 125. http://dx.doi.org/10.1186/1748717X-7-125

[29] ROESKE JC, FORMAN JD, MESINA CF, HE T, PELIZZARI CA, et al. (1995) Evaluation of changes in the size and location of the prostate, seminal vesicles, bladder, and rectum during a 
course of external beam radiation therapy. Int J Radiat Oncol Biol Phys 33: 1321-1329. http://dx.doi.org/10.1016/03603016(95)00225-1

[30] BEARD CJ, KIJEWSKI P, BUSSIERE M, GELMAN R, GLADSTONE D, et al. (1996) Analysis of prostate and seminal vesicle motion: implications for treatment planning. Int J Radiat Oncol Biol Phys 34: 451-458. http://dx.doi. org/10.1016/0360-3016(95)02081-0

[31] ANTOLAK JA, ROSEN, II, CHILDRESS CH, ZAGARS GK, POLLACK A (1998) Prostate target volume variations during a course of radiotherapy. Int J Radiat Oncol Biol Phys 42: 661-672. http://dx.doi.org/10.1016/S0360-3016(98)00248-X

[32] EL-GAYED AA, BEL A, VIJLBRIEF R, BARTELINK H, LEBESQUE JV (1993) Time trend of patient setup deviations during pelvic irradiation using electronic portal imaging. Radiother Oncol 26: 162-171. http://dx.doi. org/10.1016/0167-8140(93)90098-S

[33] BALTER JM, SANDLER HM, LAM K, BREE RL, LICHTER AS, et al. (1995) Measurement of prostate movement over the course of routine radiotherapy using implanted markers. Int J Radiat Oncol Biol Phys 31: 113-118. http://dx.doi. org/10.1016/0360-3016(94)00382-U

[34] ALTHOF VG, HOEKSTRA CJ, TE LOO HJ (1996) Variation in prostate position relative to adjacent bony anatomy. Int J Radiat Oncol Biol Phys 34: 709-715. http://dx.doi. org/10.1016/0360-3016(95)02162-0

[35] RUDAT V, SCHRAUBE P, OETZEL D, ZIERHUT D, FLENTJE M, et al. (1996) Combined error of patient positioning variability and prostate motion uncertainty in 3D conformal radiotherapy of localized prostate cancer. Int J Radiat Oncol Biol Phys 35: 1027-1034. http://dx.doi. org/10.1016/0360-3016(96)00204-0

[36] NEDERVEEN AJ, DEHNAD H, VAN DER HEIDE UA, VAN MOORSELAAR RJ, HOFMAN P, et al. (2003) Comparison of megavoltage position verification for prostate irradiation based on bony anatomy and implanted fiducials. Radiother Oncol 68: 81-88. http://dx.doi.org/10.1016/S01678140(03)00129-4

[37] AUBRY JF, BEAULIEU L, GIROUARD LM, AUBIN S, TREMBLAY D, et al. (2004) Measurements of intrafraction motion and interfraction and intrafraction rotation of prostate by three-dimensional analysis of daily portal imaging with radiopaque markers. Int J Radiat Oncol Biol Phys 60: 30-39. http://dx.doi.org/10.1016/j.ijrobp.2004.02.045

[38] ENMARK M, KORREMAN S, NYSTROM H (2006) IGRT of prostate cancer; is the margin reduction gained from daily IG time-dependent? Acta Oncol 45: 907-914. http://dx.doi. org/10.1080/02841860600907337

[39] CHEN J, LEE RJ, HANDRAHAN D, SAUSE WT (2007) Intensity-modulated radiotherapy using implanted fiducial markers with daily portal imaging: assessment of prostate organ motion. Int J Radiat Oncol Biol Phys 68: 912-919. http:// dx.doi.org/10.1016/j.ijrobp.2007.02.024

[40] LANGSENLEHNER T, DOLLER C, WINKLER P, GALLE G, KAPP KS Impact of inter- and intrafraction deviations and residual set-up errors on PTV margins. Different alignment techniques in $3 \mathrm{D}$ conformal prostate cancer radiotherapy. Strahlenther Onkol 189: 321-328. http://dx.doi.org/10.1007/ s00066-012-0303-0

[41] SIMPSON DR, LAWSON JD, NATH SK, ROSE BS, MUNDT $\mathrm{AJ}$, et al. A survey of image-guided radiation therapy use in the United States. Cancer 116: 3953-3960. http://dx.doi. org/10.1002/cncr.25129

[42] MAYLES WP Survey of the availability and use of advanced radiotherapy technology in the UK. Clin Oncol (R Coll Radiol) 22: 636-642. http://dx.doi.org/10.1016/j. clon.2010.06.014

[43] NAKAMURA K, AKIMOTO T, MIZOWAKI T, HATANO K, KODAIRA T, et al. Patterns of practice in intensity-modulated radiation therapy and image-guided radiation therapy for prostate cancer in Japan. Jpn J Clin Oncol 42: 53-57. http:// dx.doi.org/10.1093/jjco/hyr175

[44] HUANG E, DONG L, CHANDRA A, KUBAN DA, ROSEN, II, et al. (2002) Intrafraction prostate motion during IMRT for prostate cancer. Int J Radiat Oncol Biol Phys 53: 261-268. http://dx.doi.org/10.1016/S0360-3016(02)02738-4

[45] HUANG K, PALMA DA, SCOTT D, MCGREGOR D, GAEDE $S$, et al. Inter- and intrafraction uncertainty in prostate bed image-guided radiotherapy. Int J Radiat Oncol Biol Phys 84: 402-407. http://dx.doi.org/10.1016/j.ijrobp.2011.12.035

[46] LITTLE DJ, DONG L, LEVY LB, CHANDRA A, KUBAN DA (2003) Use of portal images and BAT ultrasonography to measure setup error and organ motion for prostate IMRT: implications for treatment margins. Int J Radiat Oncol Biol Phys 56: 1218-1224. http://dx.doi.org/10.1016/S0360-3016(03)00290-6

[47] MELIAN E, MAGERAS GS, FUKS Z, LEIBEL SA, NIEHAUS A, et al. (1997) Variation in prostate position quantitation and implications for three-dimensional conformal treatment planning. Int J Radiat Oncol Biol Phys 38: 73-81. http://dx.doi. org/10.1016/S0360-3016(97)00221-6

[48] MIRALBELL R, OZSOY O, PUGLIESI A, CARBALLO N, ARNALTE R, et al. (2003) Dosimetric implications of changes in patient repositioning and organ motion in conformal radiotherapy for prostate cancer. Radiother Oncol 66: 197-202. http://dx.doi.org/10.1016/S0167-8140(02)00368-7

[49] STROOM JC, KOPER PC, KOREVAAR GA, VAN OS M, JANSSEN M, et al. (1999) Internal organ motion in prostate cancer patients treated in prone and supine treatment position. Radiother Oncol 51: 237-248. http://dx.doi.org/10.1016/ $\underline{\text { S0167-8140(99)00061-4 }}$

[50] YAN D, XU B, LOCKMAN D, KOTA K, BRABBINS DS, et al. (2001) The influence of interpatient and intrapatient rectum variation on external beam treatment of prostate cancer. Int J Radiat Oncol Biol Phys 51: 1111-1119. http://dx.doi. org/10.1016/S0360-3016(01)02599-8

[51] ZELEFSKY MJ, CREAN D, MAGERAS GS, LYASS O, HAPPERSETT L, et al. (1999) Quantification and predictors of prostate position variability in 50 patients evaluated with multiple CT scans during conformal radiotherapy. Radiother Oncol 50: 225-234. http://dx.doi.org/10.1016/S0167-8140(99)00011-0 